\title{
A Framework for Organizational Compliance Management Tactics
}

\author{
Ralph Foorthuis ${ }^{1}$ and Rik Bos ${ }^{2}$ \\ ${ }^{1}$ UWV, Business Services, La Guardiaweg 116, 1040 HG Amsterdam, The Netherlands \\ Ralph.Foorthuis@uwv.nl \\ ${ }^{2}$ Utrecht University, Information and Computing Sciences, Princetonplein 5, 3584 CC Utrecht, \\ The Netherlands \\ R.Bos@Cs.uu.nl
}

\begin{abstract}
Organizational compliance with laws, industrial standards, procedures and enterprise architectures has become a highly relevant topic for both practitioners and academics. However, both the fundamental insights into compliance as a concept and the tactics for bringing an organization into a compliant state have been described in a fragmented manner. Using literature from various disciplines, this paper presents two contributions. First, it describes the fundamental concepts regarding compliance. Second, it presents a framework in which the various tactics for achieving organizational compliance can be positioned.
\end{abstract}

Keywords. Compliance management, governance, tactics, literature overview.

\section{Introduction}

With the advent of stricter legal demands, industrial best practices and prescriptive enterprise architectures, the topic of organizational compliance has become highly relevant for both practitioners and academics [1,2,3,4]. Organizational compliance can relate to various types and levels of prescriptive systems. International and domestic laws and regulations, industry-wide standards and best practices, organizational rules and procedures, and enterprise architecture principles and models can all require organizational units, projects and employees to conform to norms.

The topic of compliance has fascinated scholars for centuries. As early as the 1600s, Thomas Hobbes touched on the delicate issue of the compliance problem $[5,6,7]$. He stated that, although compliance with contracts may be better for the group as a whole and it may be in an individual actor's best interest to agree to contracts, it may very well not be in his interest to actually comply with them. Following this logic, it is necessary for policy makers to actively pursue and monitor compliance. This is also true in an organizational context, as compliance with norms may be in the best interest of the organization as a whole, but may not lead to optimal results from the perspective of the complying individuals, projects and departments. This is not merely a philosophical stance, as several studies demonstrate that non-compliance in organizations is widespread $[3,8,9]$. This makes compliance a strategic issue in the 
current era, especially considering the high costs organizations have to pay for their non-conformance. With regulations such as the Sarbanes-Oxley Act, organizations and individual CEOs and CIOs face severe penalties for non-compliance $[10,11]$. In addition, scandals and unethical firm behavior can severely damage an organization due to unsatisfied customers, shareholders, employees and other stakeholders $[1,12]$. On the other hand, demonstrating compliance with regulations, industrial best practices and ethical norms can yield a good reputation and the benefits that come with it, such as attracting large institutional investors and customers [2,9,12].

However, organizations have difficulties implementing their compliance management approaches $[13,14]$. At the same time, both the compliance stimulating tactics that comprise these approaches and the fundamental concepts regarding compliance have been described in the literature in a fragmented manner, from different perspectives and in distinct academic disciplines. Consequently, there is a need for a structured overview of generic ways in which compliance can be achieved and maintained.

The preliminary results presented in this paper are part of a larger research project, set out to identify compliance tactics acknowledged in literature from various disciplines and to offer an approach for developing an organizational compliance management strategy. This paper lays the foundations for such a research project by answering two research questions: What are the fundamental concepts in compliance? and How can compliance tactics be categorized? Our goal in presenting the preliminary results, besides the aforementioned relevance to academia and practice, is to obtain feedback that may be used in the ongoing research.

This article proceeds as follows. In section 2, our research approach is described. Section 3 defines and discusses fundamental compliance concepts. Section 4 introduces the Compliance Tactics Framework with the example tactics positioned within it to demonstrate the framework. Section 5 is for discussion and conclusions.

\section{Research Approach}

We employed a literature study for our research, as this provides an appropriate method to investigate the fundamentals of compliance and consequently develop the framework in which to position the identified tactics for achieving compliance. A literature study is also well-suited to identify the wide array of techniques devised in distinct disciplines. Science can benefit from drawing from different fields, as a topic can be enriched by the exposure to distinct and potentially relevant theoretical backgrounds [cf. 15,16]. The main disciplines we have drawn upon are law, philosophy, business studies, information systems and social psychology.

Due to space restrictions, we can only briefly describe our approach, but we have incorporated the following elements [cf. 16,17,18,19]. The most important search terms were "compliance", "conformance", "conformity", and combinations such as "compliance management" and "organi[zls]ational compliance". The search was conducted in academic indexing services, such as JSTOR and PiCarta, but also in broader listings such as GoogleScholar. The literature was collected by the principal researcher and an information specialist of Statistics Netherlands. As the nature of the study was less a 'truth finding' mission than a broad and open-minded identification effort, quality criteria for journals and conferences could not be too strict. Nonetheless, 
the norm was that a publication be academically peer reviewed, unless a technical report or practitioner publication yielded a unique insight. A literature database was created, allowing systematic storage of information on the collected publications during the actual review process undertaken. The database was based on the concept matrix of [16] and the data extraction guidelines of [18,19]. It contained information such as the titles, authors, unit of analysis and substantive conceptual contribution. In addition, a review protocol was established to ensure that the review process was carried out in a systematic fashion. As publications were reviewed, relevant texts were added to the preliminary tactics overview, which was coded by using the method of [17]. In our study, a code represented a (candidate) tactic. Using first-level coding, a preliminary categorization was conducted, resulting in summarized pieces of data and their respective codes. After 35 publications had been reviewed an iterative and creative process of pattern coding was initialized to run parallel with the continuing review and first-level coding activities, resulting in a more mature categorization of tactics. At the time of writing, we had reviewed 54 publications. This resulted in the framework and the set of example tactics as presented in section 4 of this paper.

\section{Fundamentals of Compliance}

This section defines and discusses key concepts, such as compliance, actors, norms and policies. In addition, the nature of compliance is explored in more detail, showing the insights used to structure the framework.

\subsection{Compliance: Key Concepts and Definitions}

We define compliance as a state of accordance between an actor's behavior or products on the one side, and predefined explicit rules, procedures, conventions, standards, guidelines, principles, legislation or other norms on the other [cf. 4,20,21,22]. Although we do not focus on compliance with the implicit, broader spirit of the norms, we do acknowledge relatively (high-level) principles as norms - on the condition that they be made explicit. A compliant state can be achieved regardless of the motivations, causes or circumstances that have lead to it [20,21]. In our view, therefore, an actor can be compliant without internalizing the norms and without necessarily changing his beliefs or behavior. Furthermore, unintentional compliance is also compliance. Finally, compliance should be distinguished from effectiveness, as a compliant state need not necessarily result in achieving the desired end goals [20,21].

We will use the term conformity here as equivalent to compliance, as it has been used inconsistently in the literature. We will elaborate on this below. Similar to compliance, conformity is regularly used as adherence to prescribed rules [3,21,23, $24,25,26]$. Compliance has also been contrasted with conformity, with the former following an explicit or implicit request, and the latter referring to a state of accordance in the absence of a request [27]. In this context, conformity is sometimes said to necessarily involve a change in belief or behavior [28,29], whereas an actor can be compliant without a position change (see above). Finally, according to [30] compliance is a form of conformity, representing public instead of private agreement. The term conformance, likewise, is not used in a single, specific manner 
[cf. 23,31,32]. Therefore, unless specified otherwise, we will use the terms compliance, conformity and conformance interchangeably (using the definition presented at the beginning of section 3.1).

We define an actor as a person or organizational entity who acts within an organization, is equipped with cognitive capabilities, preferences, beliefs, values and at least some degree of autonomy [6,35,36]. As such, an actor can be e.g. an organizational unit, a project or an individual employee. In the context of this paper, an actor is expected to comply with the norms. See section 3.2 for more on actors.

The terms norms and prescriptions are used interchangeably here, serving as general denotations that encompass more specific forms such as laws, standards, rules, principles and guidelines. Therefore, norms or prescriptions can refer to general, abstract (but explicit) principles or to detailed rules - or anything in between. They can also refer to prohibitive norms (so-called proscriptions). Furthermore, they can be legally required or voluntary by nature. Norms can relate to both behavior and products. Requiring a project to use the organization's standard system development method is an example of rules relating to behavior. Requiring the IT-systems delivered by the project to comply with enterprise-wide quality standards is an example of rules relating to products. Finally, norms can (and probably will) change as time progresses. A set of norms is referred to here as a policy.

When applying norms or assessing them on conformance, several aspects should be taken into account [4]. A prescription should be applied correctly. Its use, or lack of it, should also be justified (relevant) in the respective situation. Another issue is whether related prescriptions are applied consistently. A final concern is whether the complete set of (mandatory) norms is applied, as opposed to merely a convenient subset.

Another interesting aspect concerns whether norms are mandatory or not. In practice, not all norms are (e.g. industrial best practices or some enterprise architecture principles). Adherence to the norms then is more akin to the narrow sense of conformity as defined by [27], i.e. adherence without a request. Even when norms are mandatory, they are not always perceived as such in practice [33].

A distinction can be made between two types of non-compliance [cf. 24,34]. First, a transgression refers to a situation in which a norm is not complied with, e.g. by breaking a law or rule. A reason for this might be that the actor in question had no interest in conforming to this specific norm or simply did not know how to comply. Secondly, subversion refers to a situation in which an actor, for his own individual interest, attempts to undermine the entire compliance system itself, or at least an essential part of its norms. For example, when the implementation of standards is carried out in such a fashion as to demonstrate their inferiority and the need to abandon them altogether. In an organizational context, subversion might point to fundamental political problems, structural conflicts of interest or competing norm systems. An organization that is the result of a merger, for example, may have competing sets of architectural standards.

A compliance tactic is a measure that can be taken, or a technique or mechanism that can be used, to encourage compliance of relevant actors [cf. 37]. Tactics can be preventative, detective and corrective in nature [13]. As one tactic is typically not sufficient to obtain compliance, multiple tactics need to be combined into a coherent strategy. A compliance management strategy, therefore, is a general plan featuring a 
consistent set of compliance tactics that aims to bring the organization to a state that is compliant with relevant norms, at least to a sufficient level. Such a strategy can aim to achieve holistic compliance, addressing three concerns: coherent instead of fragmented compliance efforts [10,38], a long-term scope [13], and the ability to cover multiple laws, standards frameworks or internal procedures at the same time.

\subsection{The Nature of Compliance}

In this section we will discuss some fundamental insights into compliance that will form the basis for our framework. The literature on compliance distinguishes between two broad types of theory, namely rationalist and normative approaches $[3,6,9,20,21$, 39,40,41]. These theories provide distinct insights into compliance-related behavior and underlying motivations of states, firms and individuals. Rationalist models focus on the actor's calculation of benefits and costs in his decision on whether or not to comply. This approach sees actors as choosing rationally among alternatives. Game theory is a regularly used lens here to analyze behavioral motivations, using the prisoner's dilemma to model the Hobbesian compliance problem [6,42]. In this light, incentives and disincentives will alter the outcome of the actor's calculation. Therefore, one major approach used here is enforcement (or command-and-control), in which unwanted behavior is deterred by means of punishment. Rewards are an additional means in the rationalistic perspective, stimulating compliance by changing the cost-benefit calculation to the actor's advantage.

As a second perspective, normative models focus on cooperation and assistance as a way of stimulating compliance $[9,20,21,39]$. This approach views actions as based on identities, roles, obligations, and considerations of appropriate, fair and legitimate action. Normative theories do not take the stance that an actor's behavior is irrational, but tend to broaden the scope to prevent reducing the discussion to costs and benefits. Actors are imagined to follow the institutionalized rules and practices that link particular identities to particular situations. These rules need to be internalized and viewed as legitimate by those subject to them. It is acknowledged that compliance may be hindered if rules are ambiguous, complex or continuously changing, or if they are too numerous or not easily available. Non-compliance may also be the inadvertent result of deficient routines or a lack of capacity, knowledge or commitment. For all these reasons, non-compliance should be 'managed' instead of being sanctioned. Methods to increase compliance therefore often focus on increasing the actor's capacity to comply. This is effectuated by cooperating, providing support and encouraging shared discourse in order to render rules clearer, more persuasive and easier to commit to.

Rational and normative models are not mutually exclusive, but rather complement each other and provide different lenses for analyzing influences on compliance behavior $[3,9,20]$. Both perspectives are relevant to our research. For example, organization-wide standards may be dismissed for rational reasons, as conforming to them may take additional time and effort. Or it may be that the organizational units and employees value their identity as "professionals" or their role as "managers". Also, public organizations may feel "obliged", or consider it "appropriate" not to spend tax payers' money unnecessarily.

Although theories from both the rational and normative perspective often regard actors that need to comply as unitary agents, a comprehensive perspective on 
compliance also needs to be able to disaggregate an actor into multiple sub-actors $[9,20,39]$. An organization is comprised of structural units, such as departments and their sub-units, and temporary initiatives, such as programs and their projects and teams. Furthermore, all of these entities will have individual members. Motivations for compliance-related behavior may differ between these different (sub-)actors [9]. We deal with this issue in our study by acknowledging three conceptual levels. First, the level of the enterprise as a whole, in which "enterprise" can be taken to mean the entire organization, a division or even a network of organizations [cf. 31]. This is the level at which the internal policy makers are located and at which the policies are determined - although there may obviously be pressure from higher (external) levels, in the form of laws and industrial best practices. The second level accommodates various types of collectives that are expected to comply. They exist within the enterprise, such as departments and their sub-units and programs and their projects and teams. These collectives typically have a more local scope and may have a political agenda that can, at least in part, be inconsistent with the wider enterprise and its policies. The third level is that of individuals, who may themselves be expected to comply (e.g. in the case of information security procedures) or who may be part of a collective that is requested to comply (e.g. in the case of a project implementing a system that records privacy-sensitive information). In both cases, the decisions and behavior of individuals are determinants of actual compliance.

\section{The Compliance Tactics Framework}

Based on the fundamental insights discussed above, this section presents the framework within which the tactics used to stimulate compliance can be positioned. On the horizontal dimension, the characteristics of both the rationalist and the normative compliance approaches are used as defining elements. As these types of theory provide different perspectives on behavioral motivations for compliance, they can accommodate tactics of a different nature. The rationalist perspective puts forward inducements (incentives or rewards) and enforcement (disincentives or penalties), whereas the normative perspective offers management of compliance (cooperation and assistance). The vertical dimension represents the organizational level at which

\begin{tabular}{|c|c|c|c|c|}
\hline & & \multicolumn{3}{|c|}{ Compliance Management Approach } \\
\hline & & Inducements & Enforcement & Management \\
\hline \multirow{3}{*}{ 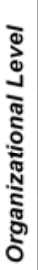 } & Enterprise & $\begin{array}{l}\text { Mandating compliance officers } \\
\text { to give incentives }\end{array}$ & $\begin{array}{l}\text { Developing guidelines for } \\
\text { punishment }\end{array}$ & $\begin{array}{l}\text { Reflecting on culture in terms of } \\
\text { compliance }\end{array}$ \\
\hline & Collective & Paying for expenses & Rejecting the project deliverable & $\begin{array}{l}\text { Conducting compliance } \\
\text { assessments }\end{array}$ \\
\hline & Individual & Offering financial rewards & Creating social disincentives & Providing performance feedback \\
\hline
\end{tabular}

Fig. 1. The Compliance Tactics Framework 
the tactics are applied, i.e. the level at which the effort is made (note that it does not necessarily denote the actor at which the tactic is directed). The enterprise level is the level at which the internal policy and its norms are formulated. This is also the level at which the compliance management strategy is developed and at which top management, compliance officers and organization-wide auditors operate. The collective level represents organizational units and temporary initiatives, such as projects, that need to conform. The individual level accommodates individual employees that are expected to comply. Figure 1 gives a visual representation of the framework. The examples positioned within it are discussed in detail below.

The framework can be used to position and characterize individual tactics. However, the framework can also be used to analyze or develop an organization's compliance management strategy, which is a general, integrated plan consisting of multiple tactics with the intention of achieving a satisfactory level of organizational compliance. As a strategy utilizes multiple tactics, it typically covers multiple cells of the framework.

\section{Examples of Tactics Used in Compliance Management}

This section will present examples of compliance tactics for each cell. Tactics are represented by italic text and can be found in the visualized framework. A first tactic at the enterprise level is mandating compliance officers to give incentives. A problem for those directly responsible for achieving compliance, e.g. security officers, is that they often have no line authority over relevant employees, including transgressors $[9,33]$. This will mean specifically that it will be very difficult for them to punish non-complying employees themselves. Rewarding complying employees, however, can be expected to be a less sensitive issue due to its positive character. Related to enforcement, developing guidelines for punishment results in enterprise-level standards, which should prevent penalties being given arbitrarily and inconsistently throughout the organization. This will increase the level of perceived fairness and consistency of the procedures (i.e. procedural justice), which is a significant determinant of compliance $[9,3,40]$. Making norms and conditions explicit may also increase their perceived 'mandatoriness', which can further increase compliance levels [33]. As a management tactic at the enterprise level, the organization can reflect on its culture in terms of compliance. This can be seen as a comprehensive and deep diagnosis of the corporate culture and its behavior in terms of compliance and ethics [12]. This need not be an incidental affair, but can be part of an ongoing process. As part of this, one goal would be to gain insight into the degree of policy-induced compliance (i.e. compliance because of the compliance system) versus externally determined compliance (e.g. a shift in values at the societal level) [21]. Reflecting also entails understanding noncompliance, which might be the result of high compliance costs, lack of technical knowledge or complex, ambiguous or difficult-to-find rules [20,21,39]. All these insights should inform the development of a new compliance management strategy.

As an incentive on the collective level, certain expenses might be paid for, as a reward for compliance. The IT costs of a project, for example, are sometimes paid for out of an enterprise-level budget on the condition that it conforms to the enterprise architecture prescriptions [4,37]. Alternatively, a project or department could be punished for non-compliance by rejecting the project deliverable [43]. This can occur, for example, if a software solution that is developed is not described in sufficient detail to meet the standards set by the party responsible for maintaining it in 
production (especially if this is an external party). Rejection need not be final, since the deliverable may be accepted after reworking it in accordance with the norms. In addition, compliance assessments of processes, systems and projects are conducted to verify whether the norms are actually complied with in practice $[4,26,44]$. The results of such an assessment or audit can be reason to take corrective action. The object of scrutiny here can be behavior, such as when it is verified whether a project conforms to the rules of the relevant project management or systems development methodology. In addition, an assessment can verify product quality by reviewing the project's design documents or by checking the delivered output of a production process against the quality standards. Because of our definition of compliance, what is central in an assessment is whether the behavior and products are consistent with the norms, not if they are consistent as a result of the norms (this latter issue can be explored in the reflecting tactic). A recent survey $(n=293)$ found the use of compliance assessments to be the most important determinant of conformance of projects to enterprise architecture prescriptions, probably due to a desire to avoid confrontation [37].

Offering financial rewards is an example of a rewarding tactic at the individual level. This can take a variety of forms, such as pay raises, promotions, awards, bonuses, days off and paid vacations [41,45]. An example of penalties for individuals is creating social disincentives. As these tend to be intangible, they might take the form of reprimands, 'naming and shaming', suspension, unfavorable mention in oral or written assessments and the consequent loss of reputation and status [9,11,41]. Providing performance feedback is a proven and inexpensive management tactic for improving employee behavior $[45,46]$. This tactic derives its power from providing the employee with objective information on his performance, preferably presented in an immediate, positive and specific fashion, with a focus on the task rather than the person. The information can trigger a performance-improving reaction within the employee, for example because he is encouraged to reduce the discrepancy between his performance and the standard or because of an inner motivation to raise the bar.

\section{Conclusions and Outlook}

This paper offers two contributions. First, we presented fundamental definitions and concepts in compliance management, based on insights from distinct academic fields. Second, we developed a framework for characterizing and categorizing compliance tactics, including an example of each category. This research is continuing, as we are currently in the process of identifying more tactics and positioning them within the framework, and studying how the framework can inform a compliance strategy.

Acknowledgements. The authors thank Annemarie Koomen, Erika Streefland, Sjaak Brinkkemper, Wiel Bruls, Nico Brand, Marlies van Steenbergen and Remko Helms.

\section{References}

1. Harris, J., Cummings, M.: Compliance issues and IS degree programs. Journal of Computing Sciences in Colleges 23(1) (2007)

2. Emmerich, W., Finkelstein, A., Montangero, C., Antonelli, S., Armitage, S., Stevens, R.: Managing Standards Compliance. IEEE Transactions on Software Engineering 25(6), 836-851 (1999) 
3. Tyler, T.R., Blader, S.L.: Can Businesses Effectively Regulate Employee Conduct? The Antecents of Rule Following in Work Settings. The Academy of Management Journal 48(6), 1143-1158 (2005)

4. Foorthuis, R.M., Hofman, F., Brinkkemper, S., Bos, R.: Assessing Business and IT Projects on Compliance with Enterprise Architecture. In: Proceedings of GRCIS 2009, CAISE Workshop on Governance, Risk and Compliance of Information Systems (2009)

5. Gauthier, D.: Why Contractarianism? In: Vallentyne, P. (ed.) Contractarianism and Rational Choice: Essays on David Gauthier's Morals by Agreement, pp. 15-30. Cambridge University Press, Cambridge (1991)

6. Hollis, M.: The Philosophy of Social Science: An Introduction. Cambridge University Press, Cambridge (1994)

7. Hartman, E.M.: Organizational Ethics and the Good Life. Oxford University Press, New York (1996)

8. Healy, M., Iles, J.: The Establishment and Enforcement of Codes. Journal of Business Ethics 39, 117-124 (2002)

9. Malloy, T.F.: Regulation, Compliance and the Firm. Temple Law Review 76 (2003)

10. Volonino, L., Gessner, G.H., Kermis, G.F.: Holistic Compliance with Sarbanes-Oxley. Communications of the AIS 14(1), 219-233 (2004)

11. Braganza, A., Franken, A.: SOX, Compliance, and Power Relationships. Communications of the ACM 50(9), 97-102 (2007)

12. Rossouw, G.J., Van Vuuren, L.J.: Modes of Managing Morality: A Descriptive Model of Strategies for Managing Ethics. Journal of Business Ethics 46, 389-402 (2003)

13. Sadiq, S., Indulska, M.: The Compliance Enabled Enterprise: Process is the Product. Compliance and Regulatory Journal 5, 27-31 (2008)

14. Hurley, J.: The Struggle to Manage Security Compliance for Multiple Regulations. White Paper, Symantec (2004)

15. Malone, T.W., Crowston, K.: The Interdisciplinary Study of Coordination. ACM Computing Surveys 26(1) (1994)

16. Webster, J., Watson, R.T.: Analyzing the Past to Prepare for the Future: Writing a Literature Review. MIS Quarterly 26(2) (2002)

17. Miles, M.B., Huberman, A.M.: Qualitative Data Analysis, 2nd edn. Sage Publications, Thousand Oaks (1994)

18. Tranfield, D., Denyer, D., Smart, P.: Towards a Methodology for Developing EvidenceInformed Management Knowledge by Means of Systematic Review. British Journal of Management 14, 207-222 (2003)

19. Kitchenham, B., Brereton, O.P., Budgen, D., Turner, M., Bailey, J., Linkman, S.: Systematic literature reviews in software engineering - A systematic literature review. Information and Software Technology 51, 7-15 (2009)

20. Zaelke, D., Kaniaru, D., Kružíková, E.: Making Law Work: Environmental Compliance \& Sustainable Development, vol. I \& II. Cameron May Ltd., London (2005)

21. Mitchell, R.B.: Compliance Theory: An Overview. In: Cameron, J., Werksman, J., Roderick, P. (eds.) Improving Compliance with International Environmental Law. Earthscan, London (1996)

22. Kim, S.: IT compliance of industrial information systems: Technology management and industrial engineering perspective. Journal of Systems and Software 80(10) (2007)

23. Merton, R.K.: Social Theory and Social Structure. Free Press, New York (1957)

24. Schapiro, T.: Compliance, Complicity, and the Nature of Nonideal Conditions. The Journal of Philosophy C(7), 329-355 (2003) 
25. Currie, W.: Institutionalization of IT Compliance: A Longitudinal Study. In: Proceedings of the 29th International Conference on Information Systems (ICIS 2008), Paris, France (2008)

26. Ellis, D., Barker, R., Potter, S., Pridgeon, C.: Information Audits, Communication Audits and Information Mapping: A Review and Survey. International Journal of Information Management 13(2), 134-151 (1993)

27. Cialdini, R.B., Goldstein, N.J.: Social Influence: Compliance and Conformity. Annual Review of Psychology 55, 591-621 (2004)

28. Zimbardo, P.G., Leippe, M.R.: The Psychology of Attitude Change and Social Influence. McGraw-Hill, New York (1991)

29. Rowe, F.: Are Decision Support Systems Getting People to Conform? The Impact of Work Organization and Segmentation on User Behaviour in a French Bank. Journal of Information Technology 20, 103-116 (2005)

30. Levine, J.M., Resnick, L.B.: Social Foundations of Cognition. Annual Review of Psychology 44, 585-612 (1993)

31. The Open Group: TOGAF Version 9: The Open Group Architecture Framework (2009)

32. Alter, S., Wright, R.: Validating Work System Principles for Use in Systems Analysis and Design. In: Proceedings of ICIS 2010, St. Louis, USA (2010)

33. Boss, S.R., Kirsch, L.J., Angermeier, I., Shingler, R.A., Wayne Boss, R.: If Someone is Watching, I'll Do What I'm Asked: Mandatoriness, Control, and Information Security. European Journal of Information Systems 18, 151-164 (2009)

34. Merriam-Webster: Merriam-Webster Online Dictionary, http://www.merriamwebster.com/dictionary/ (Date of access: January 22, 2011)

35. Jones, T.M.: Ethical Decision Making by Individuals in Organizations: An IssueContingent Model. The Academy of Management Review 16(2) (1991)

36. Thiroux, J.P.: Ethics: Theory and Practice. Glencoe Publishing Co., Inc., Encino (1977)

37. Foorthuis, R.M., Steenbergen, M., van Mushkudiani, N., Bruls, W., Brinkkemper, S., Bos, R.: On Course, But Not There Yet: Enterprise Architecture Conformance and Benefits in Systems Development. In: Proceedings of ICIS 2010, St. Louis, Missouri, USA (2010)

38. Cleven, A., Winter, R.: Regulatory Compliance in Information Systems Research: Literature Analysis and Research Agenda. In: Enterprise, Business-Process and Information Systems Modeling. LNBIP, vol. 29, pp. 174-186 (2009)

39. Chayes, A., Chayes, A.H.: On Compliance. International Organization 47(2), 175-205 (1993)

40. Li, H., Sarathy, R., Zhang, J.: Understanding Compliance with Use Policy: An Integrative Model Based on Command-and-Control and Self-Regulatory Approaches. In: Proceedings of ICIS 2010, St. Louis, USA (2010)

41. Bulgurcu, B., Cavusoglu, H., Benbasat, I.: Information Security Policy Compliance: An Empirical Study of Rationality-Based Beliefs and Information Security Awareness. MIS Quarterly 34(3), 523-548 (2010)

42. Kraus, J.S., Coleman, J.L.: Morality and the Theory of Rational Choice. Ethics 97(4), 715-749 (1987)

43. Project Management Institute: A Guide to the Project Management Body of Knowledge: PMBOK Guide, 3rd edn. Project Management Institute, Inc., Pennsylvania (2004)

44. Botha, H., Boon, J.A.: The Information Audit: Principles and Guidelines. Libri 53, 23-38 (2003)

45. Stajkovic, A.D., Luthans, F.: A Meta-Analysis of the Effects of Organizational Behavior Modification on Task Performance. The Academy of Management Journal 40 (1997)

46. Kluger, A.N., DeNisi, A.: The Effect of Feedback Interventions on Performance. Psychological Bulletin 119(2), 254-284 (1996) 